\title{
Food and micro-habitat partitioning among cyprinids in Sri Lankan hill-stream pools
}

\author{
Jacobus Vijverberg ${ }^{1 *}$, Jan Heidweiller ${ }^{2}$, Jan G. Sevenster ${ }^{2,3}$ and Koenraad Kortmulder ${ }^{2,4}$ \\ ${ }^{1}$ Netherlands Institute of Ecology (NIOO-KNAW), Droevendaalsesteeg 10, 6708 PB Wageningen, \\ the Netherlands. \\ ${ }^{2}$ Leiden University, Institute of Biology Leiden, Leiden University, The Netherlands. \\ ${ }^{3}$ Present address: Huis te Warmond, Herenstraat 141, 2361 EP Warmond, The Netherlands. \\ ${ }^{4}$ Present address: Hugo de Grootstraat 20, 2311 XL Leiden, The Netherlands. \\ *Corresponding author (k_vijverberg@yahoo.co.uk) \\ (D) http://orcid.org/0000-0003-2791-3646
}

\begin{abstract}
Cyprinid fish assemblages in three stream pools in southwest Sri Lanka, were investigated with the objective of analysing species segregation, niche complementarity and degree of resource partitioning. Feeding ecology was studied by gut contents analysis and by direct underwater observations. Dietary data were related to the microdistribution of the fish and to their horizontal distribution, the latter taken from previously published literature. Diet overlaps were calculated for each pool community and for the community as a whole. Resource partitioning among assemblage members was by diet, micro-distribution and horizontal macro-distribution. Among the three feeding substrates (rocky substrates, sand, dead leaves) rocky substrate was the most preferred, but other substrates, especially dead leaves, were used as well. Only Rasbora daniconius, which mainly fed high in the water column, fed always on rocky substrates at the relative rare occasions that it chose a firm substrate. Pethia nigrofasciata was the only species with a clear preference for sand. The assemblage could be divided into three guilds: (1) the surface feeders (Devario malabaricus, Rasbora daniconius) fed largely on terrestrial arthropods, (2) one generalist Systomus pleurotaenia which fed on all five strata, largely on terrestrial arthropods, ephemeropteran and chironomid larvae. (3) the bottom feeders (Dawkinsia singhala, Pethia cumingii, Pethia nigrofasciata, Puntius dorsalis) who fed preponderantly on chironomid larvae. Of the three niche dimensions, horizontal macro-distribution, micro-distribution and diet, horizontal distribution may be the strongest segregating factor among these fish species. The contribution of diet was substantial only between feeding guilds. A relatively high degree of endemism (ca. $40 \%$ is endemic to Sri Lanka) and habitat partitioning suggests that the cyprinid assemblages studied are predictable, co-evolved systems with competition serving as an importing structuring factor.
\end{abstract}

Keywords: fish community, niche segregation, stream fishes, small barbs, Sri Lanka, South East Asia

\section{INTRODUCTION}

The three most common mechanisms structuring ecological assemblages appear to be resource limitation, environmental variability and predation (e.g. Hairston et al. 1960; Grossman et al. 1982; Menge and Sutherland 1987). However, there has been considerable controversy about the importance of biotic factors relative to abiotic stress factors in structuring fish assemblages. Although fish assemblages in tropical streams may experience extreme flow variations during floods and droughts (e.g. Lowe-McConnell 1964; Angermeier and Karr 1983; Winemiller and Jepsen 1998), they are often structured predominantly by biological interactions such as competition and predation (e.g. LoweMcConnell 1964; Moyle and Senanayake 1984; Schut et al. 1984). In temperate streams such disturbances are often known to override biological interactions (e.g. Poff and Allan 1995; Grossman et al. 1998).

Some tropical stream communities, such as the River Duc My ecosystem in Vietnam, may be a system where both factors operate. Here, water level and thereby resources fluctuate markedly among seasons (Herder and Freyhof 2006). Similar events were reported by Zaret and Rand (1971) in a Panama lowland stream. They observed that segregation was most pronounced during the dry season when food availability was 
low. Dudgeon (1987) explained conspicuous niche overlap of fishes in a Hong Kong stream by disruption of the assemblage during the monsoon season. Several other studies have also reported minimal niche differentiation in tropical stream fish communities during the wet season (Knöppel 1970; Saul 1975; Goulding et al. 1988), suggesting that assemblages of tropical stream fishes can reflect stochastic processes during the monsoon period. In contrast, in a rainforest stream community in southeastern Brazil with a large seasonal hydrological variation, Esteves and Lobon-Cervia (2001) found no variation in diet composition between seasons. Also other studies of tropical river fish assemblages suggest that they are often predominantly structured by biological interactions (e.g. Moyle and Senanayake 1984; Schut et al. 1984; Lowe-McConnell 1987; Arunachalam 2000).

In Sri Lanka most studies on stream fishes were carried out in the wet-zone, in the southwestern part of the country. Earlier studies focused on food, feeding habits, morphological features and reproduction (De Silva and Kortmulder 1977; Kortmulder et al. 1978; De Silva et al. 1977, 1980, 1985). Later studies focused on niche segregation and the possible effect of competition as steering factor (Moyle and Senanayake 1984; Schut et al. 1984; Wikramanayake and Moyle 1989; Wikramanayake 1990; Shirantha et al. 2005). In none of these studies the availability of prey organisms in the environment were taken into account. The results of these studies suggest that the fish assemblages of southwestern Sri Lankan streams are highly structured, with segregated niches (Amarasinghe et al. 2006) where competition serves as an important structuring factor.

To test this hypothesis, the ecological structure of fish assemblages in hill stream pools in the wetzone of Sri Lanka was studied. To study feeding behavior and micro-habitat occupation we analyzed fish gut contents and carried out direct underwater observations, furthermore, the environment was sampled to quantify the availability of potential food items of the fish. In this study we focus on microhabitat occupation, because the macro-habitats of the fishes belonging to this fish assemblage were earlier described in detail by Moyle and Senanayake (1984) and Schut et al. (1984).

This study was carried out to address the following questions:
(1) Do the species segregate according to macrohabitat, micro-habitat and diet?

(2) Is there niche complementarity among species along the three niche axis: horizontal distribution, vertical micro-distribution and diet?

(3) Does the degree of resource partitioning suggest that these assemblages are predictable, co-evolved systems with competition as an important structuring factor?

\section{MATERIALS AND METHODS}

\section{Study area}

Tropical forest is confined to the south-western third of Sri Lanka because mountains (maximum elevation $2938 \mathrm{~m}$ ) intercept the prevailing winds, resulting in $200-400 \mathrm{~cm}$ of rainfall per year. The study area (Fig. 1) is situated in the wet zone of south-western Sri Lanka close to the town of Udugama. This region is characterized by high rain fall during most months of the year. Lowest rainfall was observed in August and the highest in March and November (Fig. 2). Three river pools (surface area: 442-916 $\mathrm{m}^{2}$, up to $2.0 \mathrm{~m}$ deep) in hill streams were studied (labelled A, B, C). Pool A was located in the Kondagala Ela, pools B and C in the Nannikita Ela. Both streams belong to the Gin Ganga basin. The study was conducted from June to December 1984. Pool A was sampled 13 times, pool B eight times and pool $\mathrm{C}$ seven times. A sampling trip took usually 2-4 days.

All pools were surrounded by tall trees. Pool A has a surface area of $916 \mathrm{~m}^{2}$ and is situated at $84 \mathrm{~m}$ above sea level on the border of the Kanneliya forest and the Kondagala tea estate. Pool B with a surface area of $638 \mathrm{~m}^{2}$ is situated $30 \mathrm{~m}$ above sea level near the place where the Nannikita Ela joins the Gin Ganga. This pool is highly influenced by human activities. Pool C with a surface area of $442 \mathrm{~m}^{2}$ is located at $160 \mathrm{~m}$ above sea level in the Kanneliya Forest Reserve, a second growth forest with almost no human influences. Water level fluctuations were largest in the lowest located pools A and B and smallest in the highest located pool C. The water was generally very clear, visibility measured as horizontal Secchi disc distance ranged usually between $4.0 \mathrm{~m}$ and $9.8 \mathrm{~m}$. However, heavy showers caused heavy erosion, especially in the regions of 
(a)

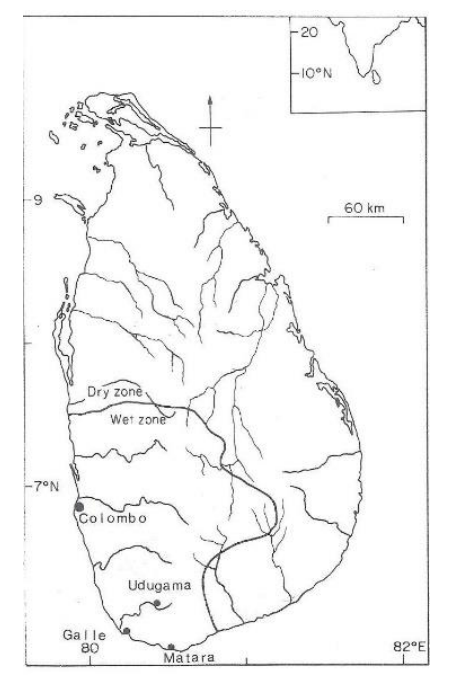

(b)
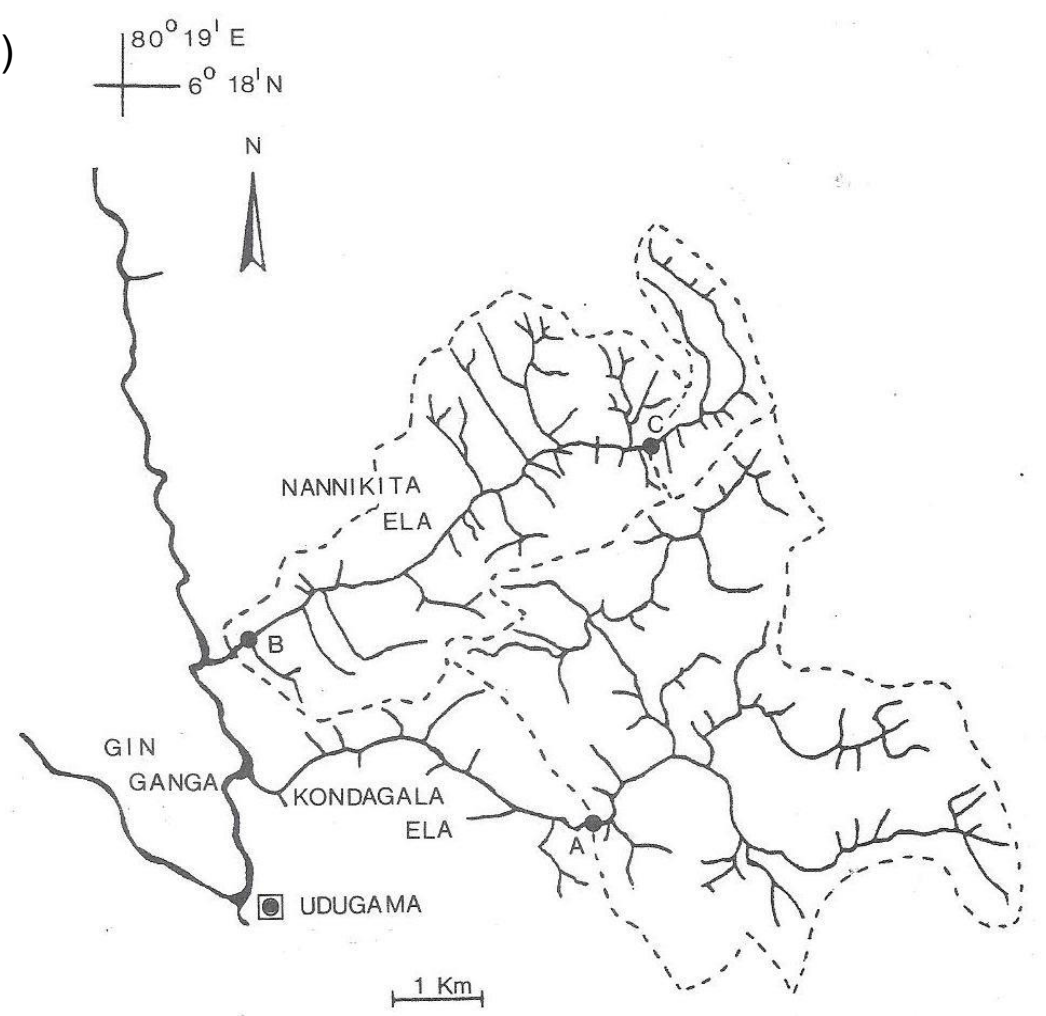

Fig. 1 (a) Sri Lanka showing the position of the study site near Udugama with the Gin Ganga River. (b) Study area showing the pool A in the Kondagala Ela, and pools B and C in the Nannikita Ela, which are tributaries of the Gin Ganga River. Broken lines indicate catchment borders.

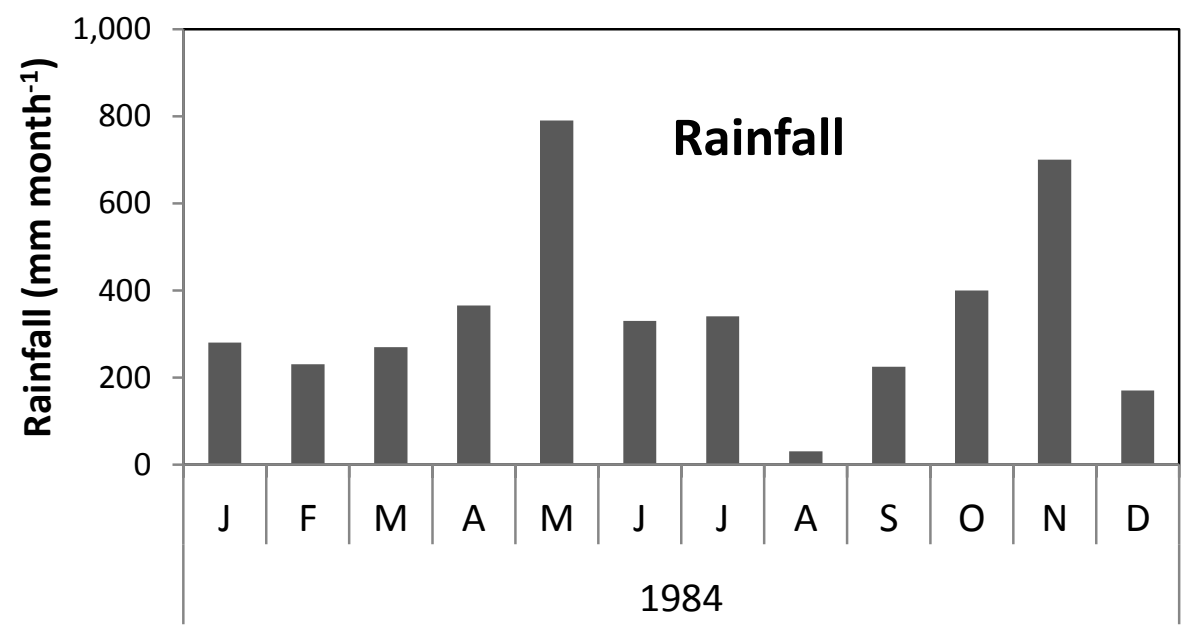

Fig. 2 Monthly rainfall (mm per month) in the study area from June 1984 until December 1984. Data from meteorological station at the Kondagala tea estate. 
pools A and B where tea estates were located, which resulted in increased sediment load directly after a heavy shower reducing visibility drastically to 0.6$1.0 \mathrm{~m}$. Water flow rates measured at one third of the depth from the surface in the inflow of the pools varied mainly among sampling dates and only little between pools. Flow rates ranged from $0.3-0.8 \mathrm{~m}$ $\mathrm{sec}^{-1}$; mean averages per pool varied from $0.40-$ $0.48 \mathrm{~m} \mathrm{sec}^{-1}$. Pools A and $\mathrm{C}$ were dominated by rocky substrates (cobble, boulders), sand was common too and occupied one third of the bottom surface (Table 1). Sand dominated in Pool B, whereas rocky-substrates were sub-dominant. After sand decaying leaves from the surrounding trees was the most common substrate.

Table 1 Substrate composition (\%) of the bottom surface areas of the three study pools A, B and C. Rocky substrates include boulder and bed rock.

\begin{tabular}{llll}
\hline Substrate & Pool A & Pool B & Pool C \\
\hline Leaves & 3.0 & 6.0 & 9.0 \\
Sand & 29.0 & 56.0 & 29.5 \\
Rocky substrates & 68.0 & 38.0 & 61.5 \\
\hline
\end{tabular}

\section{Physical parameters}

Secchi disc distance was measured horizontally at $0.5 \mathrm{~m}$ depth by scuba divers. Water flow rate was measured during each sampling trip in the middle of the stream at the inflow of the pool at one third of the depth from the surface with an electronic flowmeter.

\section{Sampling of potential fish food organisms}

The water column and three different substrate types (rocky substrates, sand and leaves) were sampled in each pool. The water column was sampled with a standard (Hydrobios) $80 \mu \mathrm{m}$ mesh zooplankton net. Ten random vertical hauls from just above the bottom to the surface were taken in the deepest region of the pool. For rocky substrates (bed rock and boulders) three samples were collected by cleaning $1 \mathrm{dm}^{2}$ surface area with knife, brush and a large pipette. Sand was sampled with a Perspex tube (length $30 \mathrm{~cm}$, diameter $5 \mathrm{~cm}$ ). The tube was pushed into the sand, the upper cork was inserted, and then the tube was slightly lifted and bottom cork was inserted. This was repeated several times at random locations until a pooled sample of $2.9-3.6 \mathrm{dm}^{2}$ was collected. Sampling dead leaves on the bottom of the pool was done by placing a small bucket upside down on this substrate, lifting it a little and pushing all leaves underneath inside. Two random samples were taken and pooled, representing a bottom surface area of $8.3 \mathrm{dm}^{2}$. The invertebrates were separated from the leaves by spraying each individual leave using a washing bottle. All samples were concentrated over $80 \mu \mathrm{m}$ mesh plankton gauze and preserved in $4 \%$ formalin.

\section{Fish sampling}

Cyprinids were collected with monofilament gill nets (1.5 m high, $15 \mathrm{~m}$ long) of 6, 8, 10 and 13 and $16 \mathrm{~mm}$ bar mesh which were operated from 10.00 a.m. to 3.00 p.m. in four different locations per pool, at two different depths (surface, bottom). The exposure time per net was 15 minutes, the sampling effort per pool per sampling date was similar. After being anesthetized with $50 \mathrm{ppm}$ Benzococaine, smaller fish was preserved in $4 \%$ formalin. Of larger fish, guts were removed and preserved in $4 \%$ formalin after the total length (TL) was taken. Fish specimens were classified to the species level according to Pethiyagoda (1991), Pethiyagoda et al. (2012) and FishBase (2017).

\section{Diet analysis}

To study fish diets, the contents of the anterior $1 / 3$ part of the gut, were analysed per species and per size class (max. 10 individuals per species per size class). The total size range of each species was divided into 3 size classes ( $\mathrm{Sc} 121-40 \mathrm{~mm}, \mathrm{Sc} 2=41$ $60 \mathrm{~mm}, \mathrm{Sc} 3>61$ ). Diet analysis was carried out in two steps. Firstly, the relative bio-volumes of plant material (mainly benthic algae), animal matter and detritus were estimated. Secondly, the bio-volume contribution of the animal matter was analysed in more detail. We distinguished 19 different taxa, which were later pooled into six major categories: Terrestrial arthropods - dominated by ants (TA), aquatic Coleoptera larvae and adults (COL), Trichoptera larvae (TR), Diptera larvae (DIP), Ephemeroptera larvae (EPH) and macrofauna rest group (MAR).The relative bio-volume contribution of the different food categories in the gut was estimated according to the point's method of Hynes (1950), using a dissection zoom microscope or a standard compound light microscope when small food items dominated. The average diet per fish species per pool was calculated by taking the average of the three size classes over the study period. Diet overlap was estimated in two different 
ways: on basis of the whole diet characterized by its main components, algae, detritus and animal matter and on basis of the animal food only (six categories).

\section{Visual underwater observations}

At the start of each observation day, a quick survey of the pool was carried out to get an impression of the species, size classes and numbers of fish present. This helped to choose suitable sites for observation. Observation sites were usually relative deep (1.0-2.0 $\mathrm{m})$ with moderate water flow rates $\left(0.1-0.3 \mathrm{~m} \mathrm{sec}^{-1}\right)$. The vertical position of the fish in the water column was studied in detail by direct underwater observations. Each observation site consisted of 3 $\mathrm{m}^{2}$ of bottom surface area and the water column above this area. Observations were carried out by scuba divers using wet suit, mask and snorkel. Observations on a specific group of fish were carried out at regular intervals, generally every 60 seconds for about 20 minutes. During one sampling day several groups of fishes were observed at different sites within the pool, the total observation period per pool adding up to 2-4 hours. The vertical position in the water column of each fish was noted, as well as its feeding activities and the substrate it selected for feeding. An observation site contained always at least two different substrates. The vertical position was noted by using a relative scale of the depth, ranging from surface $(0 \%)$ to bottom $(100 \%)$. Five different categories, viz. surface (S), high $(\mathrm{H})$ (1$25 \%$ from the surface), middle (M) (25-75\%), low (L) $(75-99 \%$ from the surface) and bottom (B) (100\%) were distinguished. A feed was recorded when a fish was seen breaking the water surface (surface-feeding), open its mouth, chew or swallow (midwater feeding) and scrape or scoop the substrate (bottom feeding).

\section{Data analysis}

For the calculation of the vertical distribution of the fish per species, the number of observed fishes in high $(\mathrm{H})$, middle $(\mathrm{M})$, low (L) and bottom (B) was expressed as numbers per quarter of the water column. Since the fishes in the middle (M) occupied $50 \%$ of the water column, these values were divided by 2 . For the number of fishes at the upper quarter, the observed numbers at the surface $(\mathrm{S})$ and those observed high $(\mathrm{H})$ in the water column were summed. In the same way, for the number of fishes in the lower quarter, the observed numbers at the bottom substrates (B) and those observed low (L) in the water column were summed. For the calculation of substrate preference, the standardized forage ratio of Paloheimo (1979) was used. This ratio excludes the effects of differences in substrate availability among pools and observation sites. The following equation was used.

$$
\mathrm{PR}_{\mathrm{i}}=\Sigma_{\mathrm{j}} \mathrm{N}_{\mathrm{pij}} / \Sigma_{\mathrm{j}}\left[\mathrm{N}_{\mathrm{pj}}\left(\mathrm{P}_{\mathrm{ij}} / 100\right)\right]
$$

where: $\mathrm{PR}_{\mathrm{i}}=$ preference ratio for substrate $i, \mathrm{~N}_{\mathrm{pij}}=$ number of fish present at substrate $i$ in observation series $j, \mathrm{~N}_{\mathrm{pj}}=$ number of fish on any substrate in observation series $j$ and $\mathrm{P}_{\mathrm{ij}} / 100=$ percentage of substrate $i$ in observation series $j$.

Diet and habitat overlaps (S) were calculated between all possible pairs of species. Diet overlaps between one pair of species, is the part of the gut contents that two species have in common. They were determined according to Schoener (1970):

$$
\mathrm{S}_{\mathrm{xy}}=\left(1-0.5 \Sigma\left|\mathrm{P}_{\mathrm{xi}}-\mathrm{P}_{\mathrm{yi}}\right|\right) * 100
$$

where: $\mathrm{S}_{\mathrm{xy}}=$ overlap (proportion) between species $x$ and species $y, \mathrm{P}_{\mathrm{xi}}=$ proportion of food type $i$ in the diet of species $x$ and $\mathrm{P}_{\mathrm{yi}}=$ proportion of food type $i$ in the diet of species $y$.

The values for this index range from 0.0 to 100.0, with 100.0 indicating complete overlap. In this study, a value of $\leq 33$ was considered to indicate low overlap, a value of $\geq 67$ high overlap and values of $>33$ to $<67$ were considered to indicate moderate overlap (Moyle and Senanayake 1984; Wikramanayake and Moyle 1989).

\section{RESULTS}

Seven cyprinid species represented more than $98 \%$ of the fish numbers caught. These were Pethia cumingii (PC), Puntius dorsalis (PD), Dawkinsia singhala (DS), Pethia nigrofasciata (PN), Systomus pleurotaenia (SP), Devario malabaricus (DM) and Rasbora daniconius (RD). Author's names, overview of abbreviations and IUCN Red List status are given in Table 2. Of the seven study species, three were endemics of Sri Lanka (DS, PC, PN) and four were vulnerable for extinction (Lower Risk, conservation dependent).

Not all seven species occurred in all pools. In pools A and C species PC, and in Pool B species PN were missing. Furthermore, in pool B only two specimens of DM and SP, and in pool C only one specimen of DM were collected (Table 3). These were not used for further calculations. Fish densities and species abundance also varied among ponds. 
Highest fish densities were observed in pool A, which was dominated by two species (DS, PD). pools B and C showed similar fish densities, pool B was dominated by PC and RD whereas pool $\mathrm{C}$ was dominated by PD and PN (Table 3).

Table 2 List of common fish species with their abbreviations caught and observed in the three stream pools. *= endemic; IUCN Red List Status: LC= Least Concern, LR= Lower Risk, cd= conservation dependent (Species names are as given in FishBase 2017).

\begin{tabular}{lll}
\hline Species & Abbr. & Status \\
\hline Dawkinsia singhala* (Valenciennes, 1844) & DS & LC \\
Devario malabaricus (Jerdon, 1849) & DM & LC \\
Pethia cumingii* (Guenther, 1868) $_{\text {Pethia nigrofasciata* (Guenther, 1868) }}$ & PC & LR, cd \\
Puntius dorsalis (Jerdon, 1849) & PD & LR, cd \\
Rasbora daniconius (Hamilton, 1822) & RD & LC \\
Systomus pleurotaenia (Bleeker, 1864) & SP & LR, cd \\
\hline
\end{tabular}

Table 3 Number of fish caught $(\mathrm{N})$, average total length and range $(\mathrm{cm})$ observed for each species in the three stream pools during the study period June until December 1984. For abbreviations of fish species names see Table $2 . \mathrm{NC}=$ not caught. $\mathrm{N} \leq 3$ not used for calculations.

\begin{tabular}{lccccccccc}
\hline Species & $\mathbf{N}$ & $\begin{array}{l}\text { Pool A } \\
\text { Average } \\
\text { Length }\end{array}$ & Range & $\mathbf{N}$ & $\begin{array}{l}\text { Pverage } \\
\text { Length }\end{array}$ & Range & $\mathbf{N}$ & $\begin{array}{c}\text { Average } \\
\text { Length }\end{array}$ & Range \\
\hline DS & 277 & 7.8 & $2.2-13.4$ & 29 & 3.3 & $2.1-4.3$ & 0 & NC & NC \\
DM & 228 & 6.7 & $4.3-9.2$ & 2 & - & - & 1 & - & - \\
PC & 0 & NC & NC & 121 & 3.0 & $2.2-4.9$ & 0 & NC & NC \\
PD & 237 & 7.3 & $3.9-15.0$ & 10 & 4.5 & $2.6-7.2$ & 173 & 5.5 & $2.6-8.2$ \\
PN & 40 & 6.0 & $2.5-9.8$ & 0 & NC & NC & 245 & 4.4 & $2.2-5.7$ \\
RD & 156 & 7.4 & $4.0-9.7$ & 96 & 3.8 & $2.1-10.3$ & 66 & 7.0 & $3.7-9.0$ \\
SP & 44 & 7.8 & $3.8-15.6$ & 2 & - & - & 12 & 7.3 & $3.8-13.6$ \\
TOTAL & 982 & & & 259 & & & 497 & & \\
\hline
\end{tabular}

\section{Food availability}

Food was available from three strata: water surface, water column and bottom substrates. Most food was provided by the bottom substrates and by terrestrial insects falling from overhanging trees on the water surface. The water column was poor in food organisms (Fig. 3). Detritus and benthic algae were dominant in bottom substrates, detritus was mainly of algal (benthic diatoms) origin. Chironomid larvae were the dominant food items in all bottom substrates and the water column, generally followed by ephemeropteran larvae and micro-fauna. In absolute terms dead leaves contained the highest biovolume of food organisms followed by rocky substrates and sand (Fig. 3). More than $98 \%$ of the terrestrial invertebrates falling out of the trees onto the water surface were ants. The invertebrates available in the bottom substrates were more diverse. In terms of biovolume, the invertebrates were dominated by chironomid larvae (53\%), whereas coleopteran larvae, ephemeropteran larvae and oligochaetes were also present in substantial biovolumes (9-12\%) (Table 4).

\section{Feeding behaviour}

The underwater observations of the feeding behaviour of the seven species showed that four species (DS, PC, PD, PN) were predominantly feeding at or close to the bottom and almost completely benthivorous. Two species (DM, RD) were predominantly feeding from the surface or high in the water column just below the surface, and one ( SP) was feeding at all five strata including the water column although benthic feeding behaviour 
was dominant (Fig. 4). Among the three substrates, rocky substrate was the most preferred for feeding, but other substrates (especially dead leaves) were used as well (Fig. 5). RD, which was mainly feeding high in the water column, was feeding on one substrate only (rocky substrates). PN was the only species with a clear preference for sand substrate.

Table 4 Relative abundance (percentage, biovolume) of potential fish food organisms in the bottom substrates of the three pools $(\mathrm{N}=36)$. Mean $\pm 1 \mathrm{SD}$. Micro-fauna include: Cladocera, Copepoda, Ostracoda, Tardigrada

\begin{tabular}{lc}
\hline Taxonomic group & Biovolume $(\%) \pm$ SD \\
\hline Acari & $0.9 \pm 1.1$ \\
Coleoptera larvae & $8.7 \pm 15.3$ \\
Coleoptera adults & $2.3 \pm 10.2$ \\
Trichoptera larvae & $0.9 \pm 3.2$ \\
Chironomid larvae & $53.3 \pm 24.8$ \\
Diptera larvae rest & $1.4 \pm 1.6$ \\
Ephemeroptera larvae & $9.3 \pm 10.9$ \\
Micro-fauna & $4.9 \pm 1.5$ \\
Nematods & $1.4 \pm 8.2$ \\
Oligochaeta & $12.0 \pm 19.8$ \\
Plecoptera larvae & $2.0 \pm 5.9$ \\
Rest Macrofauna & $2.6 \pm 12.5$ \\
TOTAL & 99.7 \\
\hline
\end{tabular}

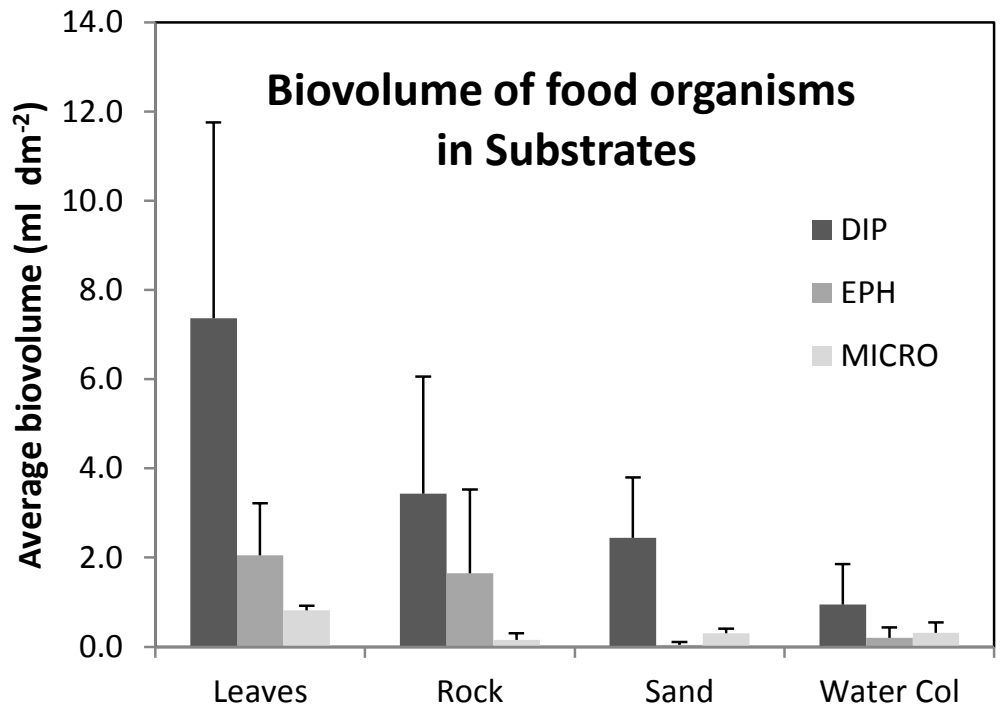

Fig. 3 Average $\pm 1 \mathrm{SD}$ of biovolume per unit of habitat $\left(\mathrm{ml} \mathrm{dm}^{-2}\right)$ of the three most common fish food organisms in the water column and three substrate types of the three pools $(\mathrm{N}=36)$. Abbreviations used: DIP = Diptera larvae, EPH = Ephemeroptera larvae and MICRO = micro-fauna. Diptera larvae (DIP) contained mainly (> 98\%) chironomid larvae. 


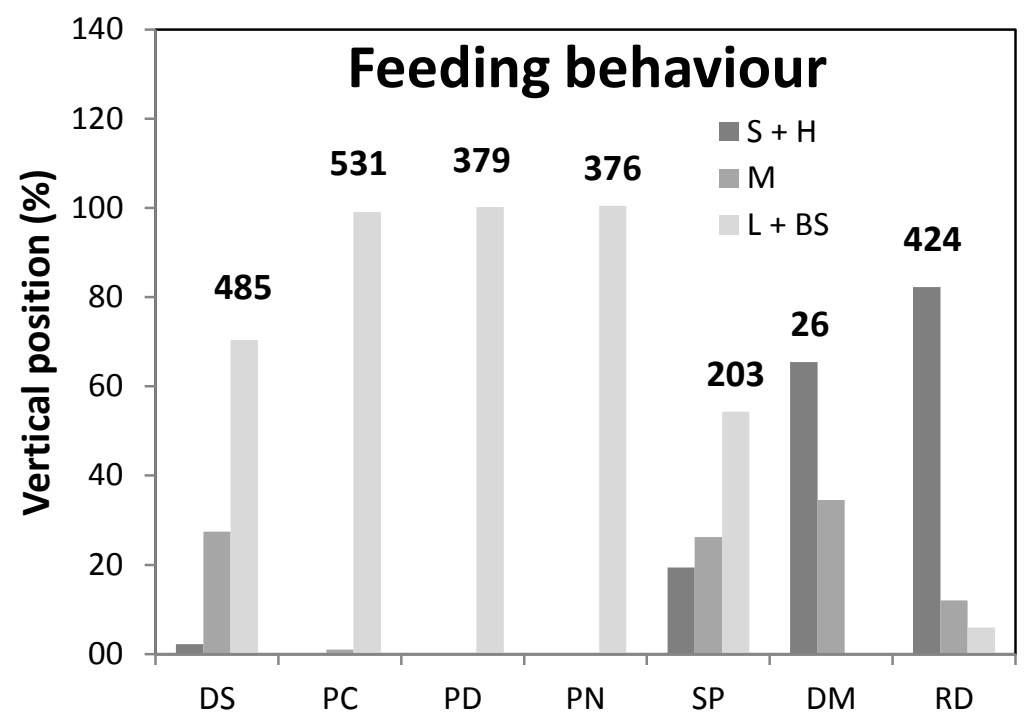

Fig. 4 Visual observations on the feeding behaviour of seven fish species at different depths. Average vertical position in the water column when feeding (\%). Abbreviations used: $\mathrm{S}=$ surface, $\mathrm{H}=$ high at a depth of $25 \%$ to the surface, $\mathrm{M}=$ middle at a depth of $25-75 \%, \mathrm{~L}=$ low at a depth of $75-99 \%$ and $\mathrm{BS}=$ bottom substrate. Species arranged according to feeding guild, from left to right: benthivores - generalist surface feeders. For abbreviations of fish species names see Table 2. Number of observations above columns.

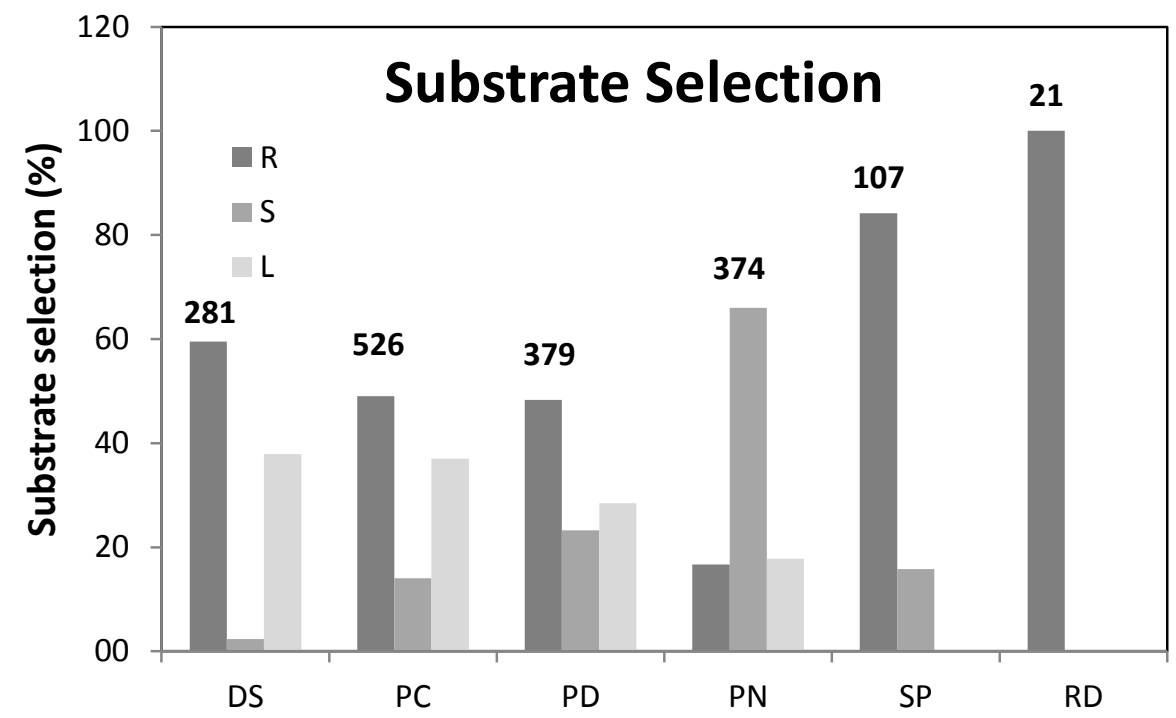

Fig. 5 Visual observations on the substrate selection of six benthic feeding fish species. Substrate preferences presented as standardized forage ratios (\%). Abbreviations used: $\mathrm{R}=$ rocky substrates, $\mathrm{S}=$ sand and $\mathrm{L}=$ leaves. For abbreviations of fish species names see Table 2. Number of observations above columns. 


\section{Diet composition}

Of the three main food types, animal food and detritus were eaten most. Algae were eaten in small quantities; they represented generally less than 5\% bio-volume of the total diet of which less than $1 \%$ was higher plants. The highest proportions of animal food were eaten by the surface feeding minor carps (DM, RD) (Fig. 6). PD and SP were eating substantial amounts of animal food; of the other carp spp. proportions of ingested animal food varied strongly among pools.

Most benthic feeding species (DS, PC, PD, PN) were feeding predominantly on chironomid larvae, whereas the generalist SP was mainly feeding on a mixed diet of chironomid larvae, ephemeropteran larvae and terrestrial insects (Table 5). The two surface feeders (DM, RD) were predominantly feeding on terrestrial insects.

\section{Diet overlap}

The diet overlap per species per pool was studied on the basis of diets characterized by the composition of the animal food only (six categories) (Table 6). The values of the overlap index range from 0.0 to 100.0 , with 100.0 indicating complete overlap. In the present study overlaps values ranged from 12 -85 .

Although the data showed substantial variation within specific species combinations, three guilds could be clearly distinguished when the low, moderate and high overlaps between and within three different groups of minor carps were compared. The benthic carp spp. (DS, PC, PD, PN) showed high and moderate overlap values among species, the generalist SP showed high and moderate overlaps with the benthic carp spp. and with the surface feeding carps (DM, RD), the surface feeding carps (DM, RD) showed low and moderate overlaps with the benthic carp spp., and high overlaps with each other (Table 7).

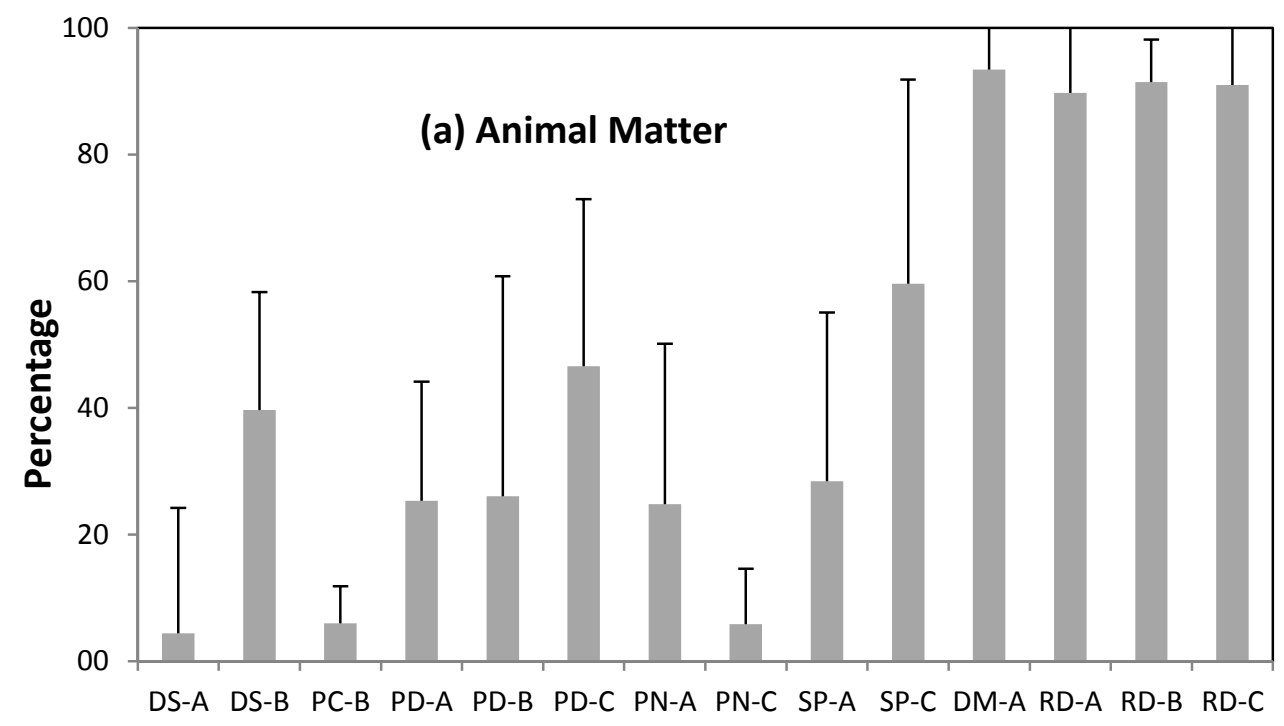

Fig. 6 Average percentage of (a) animal matter and (b) detritus in the diet (mean +1 SD) of seven fish species in stream ponds from June until December 1984. Species arranged according to feeding guild, from left to right: benthivores - generalist - surface feeders. For abbreviations of fish species names see Table 2 , for number of observations see Table 3. A, B and C denote the three stream ponds. 
Table 5 Average diet composition (mean \pm 1 SD) in percentages per fish species per pool during the study period June until December 1984. N = number of sampling dates, for number of observations see Table 3 . Six animal food categories: Terrestrial arthropods (TA), Coleoptera (COL), Trichoptera larvae (TR), Diptera larvae (DIP), Ephemeroptera larvae (EPH) and macrofauna rest group (MAR). Diptera larvae (DIP) contained mainly (> 98\%) chironomid larvae. For abbreviations of fish species names see Table 2.

\begin{tabular}{|c|c|c|c|c|c|c|c|}
\hline Pond A & $\mathbf{N}$ & TA & COL & TR & DIP & EPH & MAR \\
\hline $\mathrm{DS}$ & 10 & $25.6 \pm 19.7$ & $3.4 \pm 5.7$ & $2.6 \pm 4.5$ & $37.7 \pm 25.2$ & $23.8 \pm 16.3$ & $6.9 \pm 7.6$ \\
\hline $\mathrm{DM}$ & 11 & $59.3 \pm 23.5$ & $5.5 \pm 6.3$ & $0.7 \pm 1.2$ & $9.0 \pm 9.1$ & $24.1 \pm 16.1$ & $1.4 \pm 3.9$ \\
\hline PD & 11 & $7.3 \pm 11.0$ & $11.5 \pm 8.4$ & $1.6 \pm 3.3$ & $72.5 \pm 15.1$ & $4.8 \pm 3.0$ & $2.3 \pm 1.6$ \\
\hline PN & 8 & $0.0 \pm 0.0$ & $4.8 \pm 7.3$ & $1.5 \pm 2.7$ & $75.7 \pm 19.2$ & $17.4 \pm 20.5$ & $0.8 \pm 1.5$ \\
\hline $\mathrm{RD}$ & 10 & $71 . \overline{5}+20.5$ & $6.4+6.9$ & $0.3+0.6$ & $11.1+17.8$ & $9.9+5.6$ & $0.9+1.1$ \\
\hline SP & 8 & $37.4 \pm 41.0$ & $9.8 \pm 14.8$ & $1.5 \pm 2.0$ & $23.5 \pm 25.3$ & $27.6 \pm 25.3$ & $0.2 \pm 0.3$ \\
\hline Pond B & $\mathbf{N}$ & TA & $\mathrm{COL}$ & TR & DIP & EPH & MAR \\
\hline DS & 3 & $16.7 \pm 28.9$ & $0.0 \pm 0.0$ & $0.0 \pm 0.0$ & $39.0 \pm 34.0$ & $14.0 \pm 24.0$ & $30.4 \pm 24.0$ \\
\hline $\mathrm{PC}$ & 3 & $0.0 \pm 0.0$ & $0.0 \pm 0.1$ & $0.0 \pm 0.05$ & $54.2 \pm 42.8$ & $31.1 \pm 53.9$ & $14.7 \pm 17.4$ \\
\hline PD & 3 & $0.0 \pm 0.0$ & $0.0 \pm 0.1$ & $0.0 \pm 0.0$ & $89.0 \pm 2.7$ & $0.0 \pm 0.0$ & $10.9 \pm 2.7$ \\
\hline $\mathrm{RD}$ & 5 & $70.7 \pm 43.6$ & $0.0 \pm 0.0$ & $0.1 \pm 0.2$ & $12.2 \pm 19.4$ & $16.9 \pm 24.3$ & $0.0 \pm 0.1$ \\
\hline Pond C & $\mathbf{N}$ & TA & COL & TR & DIP & EPH & MAR \\
\hline DS & 2 & $21.7 \pm 30.7$ & $0.0 \pm 0.0$ & $1.9 \pm 2.7$ & $73.0 \pm 32.8$ & $2.4 \pm 3.4$ & $1.0 \pm 1.4$ \\
\hline PD & 6 & $12.7 \pm 18.4$ & $2.0 \pm 4.1$ & $0.4 \pm 0.6$ & $66.0 \pm 17.3$ & $14.7 \pm 15.2$ & $3.8 \pm 3.6$ \\
\hline PN & 5 & $9.8 \pm 13.6$ & $1.1 \pm 2.4$ & $1.2 \pm 1.2$ & $74.5 \pm 19.9$ & $12.6 \pm 12.3$ & $0.9 \pm 0.4$ \\
\hline $\mathrm{RD}$ & 6 & $61.6 \pm 32.7$ & $2.8 \pm 4.9$ & $0.1 \pm 0.3$ & $18.2 \pm 18.4$ & $16.1 \pm 17.9$ & $1.3 \pm 1.8$ \\
\hline SP & 5 & $34.4 \pm 38.3$ & $5.7 \pm 12.7$ & $1.4 \pm 1.9$ & $29.6 \pm 40.2$ & $19.7 \pm 23.4$ & $9.2 \pm 14.5$ \\
\hline
\end{tabular}

Table 6 Average diet overlap for each species in the three stream pools during the study period June until December 1984. Based on six animal food categories: Terrestrial arthropods, coleoptera, trichoptera larvae, diptera larvae, ephemeroptera larvae and macrofauna rest group. For abbreviations of fish species names see Table 2. Species arranged according to feeding guild, from left to right: benthivores - generalist - surface feeders.

\begin{tabular}{lcclccl}
\hline \multicolumn{7}{c}{ Pool A } \\
\hline & DS & PD & PN & SP & DM & RD \\
\hline DS & - & 57.6 & 60.8 .4 & 78.0 & 63.9 & 51.2 \\
PD & & - & 84.4 & 47.1 & 28.7 & 30.8 \\
PN & & & - & 47.4 & 32.7 & 26.9 \\
SP & & & & - & 76.9 & 66.0 \\
DM & & & & & - & 84.9 \\
\hline
\end{tabular}

\begin{tabular}{ccccl} 
& \multicolumn{4}{c}{ Pool B } \\
\hline & DS & PC & PD & RD \\
\hline DS & - & 67.7 & 49.9 & 42.9 \\
PC & & - & 65.1 & 29.1 \\
PD & & & - & 12.2 \\
\hline
\end{tabular}

\begin{tabular}{lccccl}
\multicolumn{6}{c}{ Pool C } \\
\hline & DS & PD & PN & SP & RD \\
\hline DS & - & 82.5 & 87.3 & 56.1 & 43.4 \\
PD & & - & 90.8 & 63.7 & 49.5 \\
PN & & & - & 55.2 & 42.7 \\
SP & & & & - & 72.9 \\
\hline
\end{tabular}


Table 7 Summary table of percentage of low, moderate and high overlaps between and within three different guilds of minor carps in three stream pools during the study period June until December 1984. These guilds are: benthic carp spp. (DS, PC, PD, PN), the generalist $S$. pleurotaenia and the surface feeding carps (DM, RD). Overlaps are based on average diets containing six animal food categories per fish species per pool. Overlaps: Low $=<33$, moderate $=>33$ to $<67$, High $=\geq 67$. Abbreviations used: $\mathrm{Nt}=$ number of overlaps based on average diets, $\mathrm{SP}=$ S. pleurotaenia, $\mathrm{SFC}=$ Surface Feeding Carps. For abbreviations of fish species names see Table 2, for number of observations see Table 5.

\begin{tabular}{lllll}
\hline Guilds & $\mathbf{N}_{\mathbf{t}}$ & $\begin{array}{l}\text { Low } \\
\text { overlaps }\end{array}$ & $\begin{array}{l}\text { Moderate } \\
\text { overlaps }\end{array}$ & $\begin{array}{l}\text { High } \\
\text { overlaps }\end{array}$ \\
\hline Within benthic carp spp. & 9 & 0 & 44 & 56 \\
Between SP and benthic carp spp. & 6 & 0 & 83 & 17 \\
Between SP and SFC. & 3 & 0 & 33 & 67 \\
Within SFC & 1 & 0 & 0 & 100 \\
Between benthic carp spp. and SFC & 12 & 50 & 50 & 0 \\
\hline
\end{tabular}

\section{DISCUSSION}

Of the three main food types, animal food and detritus were eaten most while algae and higher plant represented only a low proportion of the diet. It was not clear if detritus and algae were actively selected or whether they were eaten accidentally because the bottom invertebrates were hidden in a crust of benthic algae with detritus. Since fish are opportunistic feeders, the most available food items were eaten most by all fish species. The water column was very poor in food items, thus it was not surprising that five of the six fish species were either eating benthic invertebrates, mainly chironomids, in or near the bottom, or terrestrial invertebrates, mainly ants, falling out of the trees. Only one fish species (SP) was eating at all strata and its diet contained chironomid larvae, ephemeropteran larvae and terrestrial insects. Four of the five benthic feeding species selected rocky substrates (cobble, boulder) for feeding and only PN selected sand substrate. RD and DM were eating predominantly from the surface; but RD was also feeding in the water column and from rocky substrates.

The vertical position of the fish species while feeding agrees well with most other authors who investigated niche segregation in hill streams of south-western Sri Lanka (Moyle and Senanayake 1984; Schut et al. 1984; Wikramanayake and Moyle 1989). However, the diet results differed. In contrast with most other authors, a relatively small contribution of algae and higher plant remains (generally $<5 \%$, biovolume) and a relatively high contribution of detritus for all species except for the two surface feeders (De Silva and Kortmulder 1977; De Silva et al. 1980; Moyle and Senanayake 1984; Wikramanayake and Moyle 1989) were noted in the present study. The low contribution of algae to the diet may be caused by differences in interpretation of the gut contents during the present study as well as by other authors. The detritus observed in the guts of the benthivorous feeding species existed for a large part of what could be believed to be dead benthic diatoms. Since the cobbles and boulders were covered by a thick crust of benthic algae with detritus, it was difficult to decide what was dead and what was alive. Therefore, the proportions of algae in the diets may have been underestimated, and the proportions of detritus may have been overestimated. The low contribution of higher plants in the diets is certainly caused by the lack of macrophytes in and around the river pools.

Only the micro-habitat characteristics of the 7 cyprinid species in the hill streams of the wet-zone of southwestern Sri Lanka were investigated during the present study. Since the macro-habitat characteristics of these species in this region were previously studied in detail by Moyle and Senanayake (1984) and Schut et al. (1984) their results were also reviewed. At the level of macrohabitat, the species segregate on the basis of rate of water flow, depth of the water column, the absence or presence of structures and on substrate types. DS and $\mathrm{PC}$ remain in very slow flowing water, PD and $\mathrm{PN}$ in slow flowing water, RD in slow-intermediate slow flowing water and DM and SP in water with a high flow rate (Table 8). The species which do not 
segregate on the basis of flow rate, segregate either on water depth or the presence/absence of structures.

The micro-level segregation was less strong, especially within the benthic carp spp. guild and within the guild of surface feeding cyprinids (SFC), vertical distribution and diet overlaps were high or moderate. Also the generalist SP showed high and moderate overlaps in distribution and diet with both SFC and benthic carp spp. groups. On the other hand, there was a strong segregation in diets and micro-distribution between SFC and benthic carp spp. groups. Results of the present study largely agree with those of Moyle and Senanayake (1984) and Arunachalam et al. (1997) who also observed low diet overlap between feeding groups and moderate to high overlaps within feeding groups. However, the present study indicates that the assemblage members rely heavily on allochthonous food (ca. $40 \%$ of the spp.), whereas in contrast Moyle and Senanayake (1984) found a heavy reliance on autochthonous materials.
Of the three niche dimensions (horizontal distribution, vertical micro-distribution and diet), horizontal distribution accounted for the majority of segregations among fish species. Micro-distribution and diet contributed only partly as only differences between feeding groups were substantial. This agrees with previous research that most species which are not clearly segregated on basis of food or microhabitat occur in different habitats and rarely encounter each other (Schut et al. 1984).

A relatively high degree of endemism and a high degree of resource partitioning suggests that the studied cyprinid assemblages are predictable, coevolved systems with competition serving as an importing structuring factor. This agrees with previous studies on niche segregation of fish species in hill streams of souhwestern Sri Lanka (Moyle and Senanayake 1984, Wikramanayake and Moyle 1989).

Table 8. Macro-habitat characteristics of 7 cyprinid species in de hill streams of the wet-zone of SW Sri Lanka according to Moyle and Senanayake (1984) and Schut et al. (1984). All species can be found in stream pools. Observations of Schut et al. (1984) were carried out from January 1979 to April 1980 and of Moyle and Senanayake (1984) from January 1981 to March 1981. All information about RD and DM is based upon Moyle and Senanayake (1984), all other information upon Schut et al. (1984). Structures present are places where the water body is broken by one or more of the following objects: boulders, logs, bare tree roots, densely packed branches or dense underwater vegetation. For abbreviations of fish species names see Table 2. Species arranged according to feeding guild: benthivores - generalist - surface feeders.

\begin{tabular}{llll}
\hline Species & Water flow rate & Depth & $\begin{array}{l}\text { Structures } \\
\text { present }\end{array}$ \\
\hline DS & very slow & Deep $>100 \mathrm{~cm}$ & No \\
PC & very slow & Deep; $>80 \mathrm{~cm}$ & Yes \\
PD & Slow & Intermediate - deep; 50 to $>80 \mathrm{~cm}$ & Yes \\
PN & Slow & Shallow; $<50 \mathrm{~cm}$ & Yes \\
SP & High & Deep; $>80 \mathrm{~cm}$ & Yes \\
DM & High & Intermediate - deep; 21 to $60 \mathrm{~cm}$ & No \\
RD & Slow-intermediate & Intermediate - deep; 11 to $60 \mathrm{~cm}$ & No \\
\hline
\end{tabular}

\section{Acknowledgements}

This study was a scientific cooperation between the Department of Zoology, University of Ruhuna (Sri Lanka), Leiden University (The Netherlands) and the Netherlands Institute of Ecology (NIOO) of the Royal Netherlands Academy of Sciences. The Office of International Cooperation of the Leiden University provided financial support. We thank Dr. Sena S. De Silva, Professor of Zoology in the University of Ruhuna at the time of the study, for research facilities and scientific discussions and Professor M.J.S. Wijeyaratne, University of Kelaniya for useful comments and suggestions which greatly improved the paper. It is publication number 6310 of the Netherlands Institute of Ecology (NIOO-KNAW). 


\section{REFERENCES}

Amarasinghe, U.S., R.R.A.R. Shirantha and M.J.S. Wijeyaratne 2006. Some aspects of ecology of endemic freshwater fishes of Sri Lanka. pp. 113-124. In. C.N.B. Bambaradeniya (ed.). The Fauna of Sri Lanka: Status of Taxonomy, Research and Conservation. The World Conservation Union, Sri Lanka and the Government of Sri Lanka. $308 \mathrm{pp}$

Angermeier P. L. and J. W. Karr 1983. Fish communities along environmental gradients in a system of tropical streams. Environmental Biology of Fishes 9: 117-135.

Arunachalam M., K.C. Madhusoodanan Nair, J. Vijverberg and K. Kortmulder 1997. Food and habitat partitioning among fishes in stream pools of a southern Indian river. International Journal of Ecology and Environmental Sciences 23: 271295.

Arunachalam M. 2000. Assemblage structure of stream fishes in the Western Ghats (India). Hydrobiologia 430: 1-31.

De Silva S.S. and K. Kortmulder 1977. Some aspects of the biology of three species of Puntius (=Barbus), endemic to Sri Lanka. Netherlands Journal of Zoology 27: 182-194.

De Silva S.S., K. Kortmulder and M.J.S. Wijeyaratne 1977. A comparative study of the food and feeding habits of Puntius bimaculatus and $P$. titteya (Pisces, Cyprinidae). Netherlands Journal of Zoology 27: 253-263.

De Silva S.S., P.R.T. Cumaranatunga and C.D. De Silva 1980. Food, feeding ecology and morphological features associated with feeding of four co-occurring cyprinids (Pisces: Cyprinidae). Netherlands Journal of Zoology 30: 54-73.

De Silva S.S., J. Schut and K. Kortmulder 1985. Reproductive biology of six Barbus species indigineous to Sri Lanka. Environmental Biology of Fishes 12: 201-218.

Dudgeon D. 1987. Niche specificities of four fish species (Homalopteridae, Cobitidae, Gobiidae) from a Hong Kong forest stream. Archiv für Hydrobiologie 108: 349-364.

Esteves K.E. and J. Lobon-Cervia 2001. Composition and trophic structure of a fish community of a clear water Atlantic rainforest stream in southeastern Brazil. Environmental Biology of Fishes 62: 429-440.

FishBase 2017. Fish data base http://www.fishbase.org. WorldFish Center, Penang, Malaysia. (Accessed on February 6, 2017).

Grossman G.D., P.B. Moyle and J.O. Whitaker Jr. 1982. Stochasticity in structural and functional characteristics of an Indiana stream fish assemblage: a test of community theory. American Naturalist 120: 423-454.

Grossman G.D., R.E. Ratajczak Jr., M. Crawford and M.C. Freeman 1998. Assemblage organization in stream fishes: effects of environmental variation and interspecific interactions. Ecological Monographs 68: 395420.

Goulding M., M.L. Carvalho and E.G. Ferreira 1988. Rio Negro, Rich Life in Poor Water. Amazonian Diversity and Food chain Ecology as Seen Through Fish Communities. The Hague: SPB Academic Publishing.

Hariston G., F.E. Smith and L.B. Slobodkin 1960. Community structure, population control, and competition. American Naturalist 94: 421-425.

Herder F. and J. Freyhof 2006. Resource partitioning in a tropical stream fish Assemblage. Journal of Fish Biology 69: 571-589.

Hynes H.B.N. 1950. The food of fresh-water sticklebacks (Gasterosteus aculeatus and Pygosteus pungitius) with a review of methods used in studies of the food of fishes. Journal of Animal Ecology 19: 36-58.

Knöppel H.A. 1970. Food of central Amazonian fishes. Contribution on the nutrient-ecology of Amazonian rain forest stream. Amazon 11: 257352.

Kortmulder K., E.J. Feldbrugge and S.S. De Silva 1978. A combined field study of Barbus (= Puntius) nigrofasciatus Günther (Pisces; Cyprinidae) and water chemistry of its habitat in Sri Lanka. Netherlands Journal of Zoology 28: 111-131.

Lowe-McConnell R. H. 1964. The fishes of the Rupununi savanna district of British Guiana, South America. Part I. Ecological groupings of fish species and effects of the seasonal cycle on the fish. Journal of the Linnaean Society (Zoology) 45: 103-144. 
Lowe-McConnell R. H. 1987. Ecological Studies in Tropical Fish Communities. Cambridge, Cambridge University Press.

Menge B.A. and J.P. Sutherland 1987. Community regulation: variation in disturbance, competition, and predation in relation to environmental stress and recruitment. American Naturalist 130: 730757.

Moyle P.B. and F.R. Senanayake 1984. Resource partitioning among the fishes of rainforest streams in Sri Lanka. Journal of the Zoological Society (London) 202: 195-223.

Paloheimo J.E. 1979. Indices of food preference by a predator. Journal of the Fisheries Research Board of Canada 36: 470-473.

Pethiyagoda R. 1991. Freshwater Fishes of Sri Lanka. World Heritage Trust. Colombo, Sri Lanka. 362 p.

Pethiyagoda R., M. Meegaskumbura, K. Maduwage 2012. A synopsis of the south Asian fishes referred to Puntius (Pisces: Cyprinidae). Ichthyological Exploration of Freshwaters 23: 69-95.

Poff N.L. and J.D. Allan 1995. Functional organization of stream fish assemblages in relation to hydrological variability. Ecology 76 : 606-627.

Saul W.G. 1975. An ecological study of fishes at a site in upper Amazonian Ecuador. Proceedings of the National Academy of Science (Philadelphia) 127: 93-134.
Schoener T.W. 1970. Non synchronous spatial overlap of lizards in patchy habitats. Ecology 51: 408-418.

Schut J.A., S.S. De Silva and K. Kortmulder 1984. Habitat associations and competition of eight Barbus (= Puntius) species indigenous to Sri Lanka (Pisces: Cyprinidae). Netherlands Journal of Zoology 34: 159-181.

Shirantha, R.R.A.R., M.J.S. Wijeyaratne and U.S. Amarasinghe 2005. Food niche segregation among co-occurring endemic fish species in Sri Lanka. Sri Lanka Journal of Aquatic Sciences 10: 19-34. DOI:http://doi.org/10.4038/sljas.v10i0.7457

Wikramanayake E.D. and P.B. Moyle 1989. Ecological structure of tropical fish assemblages in wet-zone streams. Journal of the Zoological Society (London) 218: 503-526.

Wikramanayake E.D. 1990. Ecomorphology and biogeography of a tropical stream fish assemblage: evolution of assemblage structure. Ecology 71: 1756-1764.

Winemiller K. O. and D.B. Jepsen 1998. Effects of seasonality and fish movement on tropical river food webs. Journal of Fish Biology 53 (suppl. A): $267-296$.

Zaret T.M. and A.S. Rand 1971. Competition in tropical fishes: support for the competitive exclusion principle. Ecology 52: 336-342. 